\title{
Plant Age Influences Microbiome Communities More Than Plant Compartment in Greenhouse-Grown Creeping Bentgrass
}

\author{
Joseph R. Doherty, ${ }^{1}$ Jo Anne Crouch, ${ }^{2}$ and Joseph A. Roberts ${ }^{1, \dagger}$ \\ ${ }^{1}$ Department of Plant Science and Landscape Architecture, University of Maryland, College Park, MD 20742 \\ ${ }^{2}$ Mycology \& Nematology Genetic Diversity \& Biology Laboratory, United States Department of Agriculture-Agricultural Research Service, \\ Beltsville, MD 20705
}

Accepted for publication 21 June 2021.

\begin{tabular}{|c|c|}
\hline \multicolumn{2}{|c|}{ ABSTRACT } \\
\hline $\begin{array}{l}\text { Creeping bentgrass (Agrostis stolonifera) is widely used in golf } \\
\text { course settings for its desirable playing surface characteristics; } \\
\text { however, it is highly susceptible to diseases that can disrupt } \\
\text { surface integrity and cause significant losses despite } \\
\text { preventative management. Understanding the influence of early } \\
\text { plant growth and basic management practices on microbiome } \\
\text { communities are crucial first steps to developing future efforts to } \\
\text { harness the microbiome for plant health. This study investigated } \\
\text { bacterial and fungal communities of creeping bentgrass foliage } \\
\text { and rhizosphere through } 6 \text { months postemergence under a } \\
\text { controlled environment to elucidate microbiome community } \\
\text { dynamics in response to plant age. We hypothesized that plant } \\
\text { compartments will host distinct community structures and exhibit } \\
\text { different responses to plant age. Our results showed that } \\
\text { predominant bacterial phyla and fungal classes remain } \\
\text { consistent across time and plant compartment. However, genus- } \\
\text { level classification revealed that bacterial taxa differed across }\end{array}$ & $\begin{array}{l}\text { plant compartment while fungal taxa remained consistent. Host } \\
\text { influence over the microbiome manifests quickly, with the largest } \\
\text { shift in both microbial communities occurring between emer- } \\
\text { gence and } 2 \text { months postemergence. For example, Burkholderia } \\
\text { and Penicillium spp. were present at high relative abundance at } \\
\text { emergence but, by } 2 \text { months postemergence, both taxa } \\
\text { decreased significantly. Bacterial communities continued to } \\
\text { experience significant fluctuation in rare taxa from } 2 \text { months } \\
\text { postemergence onward, while fungal community structure was } \\
\text { driven by the fluctuation of the most common taxa. These results } \\
\text { highlight the connection between plant age and microbial com- } \\
\text { munity structure in creeping bentgrass in addition to underscor- } \\
\text { ing future research efforts in creeping bentgrass microbiome } \\
\text { manipulation for plant health. } \\
\text { Keywords: amplicon sequence variants, microbiome, MiSeq, } \\
\text { next-generation sequencing, turfgrass }\end{array}$ \\
\hline
\end{tabular}

Golf course putting greens receive frequent applications of synthetic fertilizers and fungicides throughout the year to meet nutritional needs (Turner 2013) and to protect the turfgrass from pathogens (Latin 2011). Reducing these synthetic inputs and making turfgrass management more environmentally sustainable may be possible

Current address of J. A. Roberts: Plant and Environmental Sciences Department, Clemson University, Florence, SC 29506, U.S.A.

Corresponding author: J. A. Roberts: jar7@ clemson.edu

Funding: Funding for this project came from the University of Maryland and United States Department of Agriculture-Agricultural Research Service project 8042-22000-298-00-D.

*The $e$-Xtra logo stands for "electronic extra" and indicates that supplementary materials are published online.

The author(s) declare no conflict of interest. distributed under the CC BY-NC-ND 4.0 International license. through utilizing the plant microbiome. The plant microbiome is a key factor in determining plant health and productivity (Berendsen et al. 2012; Lambers et al. 2009) and, through manipulation of the plant microbiome, it is possible to reduce incidence of plant disease (Andrews 1992), increase agricultural productivity (Bakker et al. 2012), and reduce chemical inputs (Adesemoye et al. 2009). However, developing effective and reliable methods to harness the microbiome as a management tool is confounded by external factors in field-based microbiome studies.

Seasonal environmental variations are shown to impact plantassociated microbial communities in turfgrass and other cultivated grasses. Beirn et al. (2016) showed significant changes in the rhizosphere bacterial and archaeal communities of an annual bluegrass (Poa аппиа L.) putting green when sampled over a 12-month period. Additionally, several warm- and cool-season turfgrasses were observed to have lower microbial biomass in September and higher biomass in May and December (Yao et al. 2011). Similarly, in a multiyear study of the switchgrass (Panicum virgatum L.) phyllosphere, discrete seasonal groups of bacterial taxa were observed at early, mid, and late season (Grady et al. 2019). However, under field 
conditions, it is impossible to ascertain whether these changes are driven by the environment directly or by changes in plant physiology brought on by the environment.

Plant microbiome composition can fluctuate in response to plant management practices; however, research has shown mixed results. In turfgrass systems, repeated fungicide applications on a creeping bentgrass (Agrostis stolonifera L. 'A1') putting green significantly reduced foliar populations of bacteria, fungi, fluorescent Pseudomonads, or actinomycetes, depending on the fungicide applied (Doherty et al. 2017). However, a more invasive turfgrass renovation project at the National Mall in Washington, DC, wherein the rootzone was completely altered, did not appreciably change the rhizosphere bacterial communities when compared with the prerenovation (Crouch et al. 2017). Similarly, in other grass microbiomes, management practices showed varying results. Gdanetz and Trail (2017) observed that, in the wheat (Triticum aestivum L.) microbiome, both bacteria and fungi colonizing all plant organs were unaffected when comparing growth under conventional or organic management practices. However, Hartmann et al. (2014) previously found significant differences in rhizosphere bacterial and fungal communities of winter wheat and grass-clover rotations when comparing long term organic and conventional management. More recently, fertilization practices were shown to enrich Proteobacteria and Acidobacteria in the rhizosphere of a 2-year-old stand of Miscanthus $\times$ giganteus; however, rhizosphere bacterial communities of a 4-year-old stand of Miscanthus $\times$ giganteus showed a reduced response to fertilization practices (Ma et al. 2021).

The varying impacts that environmental factors and management practices have on microbiome composition under field conditions highlights the need for controlled-environment research to ascertain different components of microbiome community dynamics. Much of what is known about the turfgrass microbiome comes from studies performed under field conditions. Although research under field conditions is invaluable for developing management recommendations, basic research on the turfgrass microbiome under controlled environmental conditions is necessary to understand the underlying fundamentals of microbiome community dynamics. Our previous work on the creeping bentgrass microbiome was conducted under sterile growth conditions with autoclaved growth medium in a controlled environment, which allowed us to learn how the microbiome of juvenile creeping bentgrass was influenced by resident seed and soil microbiota, without the confounding effects of external inoculum and environmental variations (Doherty et al. 2020). However, that research was limited to a 6-week time frame and did not evaluate external influences or long-term community dynamics in response to plant age. Therefore, here, we set out to characterize the developing creeping bentgrass microbiome over time across different plant compartments (i.e., foliage and rhizosphere). The study was completed in a greenhouse setting to emphasize the influence of plant edaphic factors on the microbiome while providing an intermediate between sterile growth and field conditions. We hypothesized that the turfgrass foliage and rhizosphere would host different microbial communities and that, within each compartment, the communities would exhibit different variations over time. Characterizing the developing creeping bentgrass microbiome under controlled conditions will provide reference for future field studies aimed at manipulating the microbiome for improving creeping bentgrass health.

\section{MATERIALS AND METHODS}

Growth conditions. To minimize external influences on the turfgrass microbiome and ascertain temporal shifts in microbial populations driven by plant maturity, this experiment was conducted in a controlled-environment greenhouse at the Research Plant Growth
Facility at the University of Maryland, College Park, MD. Seed of creeping bentgrass cultivar 007 were planted into four replicate SC10 cone-tainers $(3.81$ by $20.96 \mathrm{~cm}$; Stuewe \& Sons, Inc., Tangent, OR, U.S.A.) filled with a soil medium of $85 \%$ sand and $15 \%$ sphagnum peat moss ( $\mathrm{vol} / \mathrm{vol}$ ) by pressing the seed $6 \mathrm{~mm}$ into the soil surface. Cone-tainers were maintained in the greenhouse until 6 months following seedling emergence. Irrigation was provided daily through an overhead misting system. Nutrients were provided every 14 days as $10 \mathrm{ml}$ of sterilized half-strength Hoagland's solution (Hoagland and Arnon 1950). Creeping bentgrass plants were cut weekly with flame-sterilized scissors to a height of $1.27 \mathrm{~cm}(0.5 \mathrm{in})$, a typical height of cut for a golf course fairway. Greenhouse temperatures were maintained at $25^{\circ} \mathrm{C}\left(77^{\circ} \mathrm{F}\right)$ during the day and $23^{\circ} \mathrm{C}\left(73^{\circ} \mathrm{F}\right)$ at night. Two experimental runs were conducted, with initiation dates staggered 1 month apart in summer 2017.

Sample collection and processing. Samples, consisting of three whole creeping bentgrass plants, were collected from each cone-tainer at emergence and 2, 4, and 6 months postemergence. Foliar and rhizosphere samples were separated at the chlorophyll line at sampling using flame-sterilized forceps and placed into autoclaved coin envelopes (number 3; Staples, Framingham, MA, U.S.A.). Rhizosphere samples were shaken by hand to dislodge bulk soil not adhered to roots. Bulk soil samples were collected with the 6-month postemergence plant samples. Samples were immediately placed on ice to minimize changes to the microbial communities during transportation. All samples were stored at $-20^{\circ} \mathrm{C}$ until processed.

Environmental DNA (eDNA) was extracted from foliar samples using a modified protocol for the Qiagen DNeasy Plant Mini Kit (Qiagen, Gaithersburg, MD, U.S.A.), as described (Doherty et al. 2020). Briefly, samples were incubated overnight in solution AP1 (Qiagen) at $65^{\circ} \mathrm{C}$, followed by tissue disruption on a FastPrep-24 (MP Biomedicals, Santa Ana, CA, U.S.A.), and the extraction process then followed the manufacturer's protocol. Rhizosphere and bulk soil eDNA were extracted with the Qiagen PowerSoil kit (Qiagen) using an alternate protocol for low-biomass soils, as previously described (Beirn et al. 2016). Before following the manufacturer's protocol, $200 \mu \mathrm{l}$ of the PowerSoil bead tube solution was replaced with an equal volume of 25:24:1 chloroform/phenol/isoamyl alcohol ( $\mathrm{pH}$ 8) (VWR, Radnor, PA, U.S.A.), $0.25 \mathrm{~g}$ of soil was added along with $60 \mu \mathrm{l}$ of solution $\mathrm{C} 1$, and the tubes were run on a FastPrep-24 (MP Biomedicals) before returning to the manufacturer's protocol.

DNA manipulations. Quality and concentration of extracted eDNA were measured using a Nanodrop 1000 (Thermo Fisher Scientific, Waltham, MA, U.S.A.) and a Qubit fluorometer (Life Technologies, Grand Island, NY, U.S.A.), respectively. Extracted eDNA was

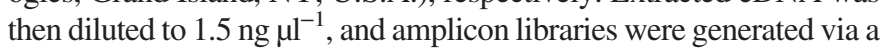
previously described two-step PCR process (Beirn et al. 2016). Illumina adapter sequences were added to the $5^{\prime}$ end of each primer (Beirn et al. 2016). Four versions of reverse primers were synthesized with 0 to 3 mixed sequence bases (where $\mathrm{N}$ is any nucleotide) and combined into an equimolar mixture for subsequent PCR assays to increase sequencing diversity, because low-diversity libraries can result in low-quality base calls (Fadrosh et al. 2014). Bacterial 16S amplicons were generated using the $\mathrm{Ba} 9 \mathrm{~F} / \mathrm{Ba} 515 \mathrm{Rmod} 1$ primer pair (approximately 500 bp) (Kittelmann et al. 2013; Weisburg et al. 1991), while the fungal internal transcribed spacer (ITS)2 region was amplified using the ITS3_KYO2/ITS4-R primer pair (approximately 350 bp) (Toju et al. 2012; White et al. 1990). PCR assays, purification, and Illumina index incorporation were all performed as previously described (Beirn et al. 2016).

Indexed libraries were cleaned using HighPrep PCR (MagBio Genomics, Gaithersburg, MD, U.S.A.) with a modified protocol for targeted removal of any sequence fragments $<200 \mathrm{bp}$. The QIAxcel Advanced (Qiagen) and Qubit fluorometer (Life Technologies) 
were used to determine fragment size and DNA concentration for each purified library. Sequencing was performed on the Illumina MiSeq platform as paired-end reads $(2 \times 300)$ using a 600 -cycle MiSeq v.3 reagent cartridge (Illumina). For each experimental run, three technical replicates were sequenced. All sequences were output in FASTQ format. Raw sequence data are accessible via the NCBI Sequence Read Archive as project PRJNA704926.

Sequence analysis. All sequence data were subjected to preprocessing and data analysis in the $\mathrm{R}$ environment ( $\mathrm{R}$ Core Team 2017) as described by Doherty et al. (2020). Briefly, primers and sequencing adapters were removed from the data set using cutadapt 1.9.1 (Martin 2011). Cleaned reads were processed through the DADA2 1.6 pipeline (Callahan et al. 2016) for quality control, error correction, and to infer amplicon sequence variants (ASVs). Taxonomy was assigned using a DADA2 formatted release of the GreenGenes v.13.8 database (Callahan 2016; McDonald et al. 2012) for bacteria and the UNITE v.7.2 database (Kõljalg et al. 2013) for fungi. Diversity and statistical analyses were performed using the phyloseq (McMurdie and Holmes 2013) and vegan (Oksanen et al. 2017) R packages. Unless otherwise stated, a $P$ value $\leq 0.05$ was considered significant. Graphics were generated using the ggplot2 package (Wickham 2009) in R.

$\alpha$ Diversity was measured using the Shannon diversity index (Spellerberg and Fedor 2003). No rarefaction was performed for estimation of $\alpha$-diversity metrics because these metrics are not sample size dependent (McMurdie and Holmes 2014). Significant differences in $\alpha$ diversity between samples were determined using a nonparametric Kruskal-Wallis test, with Benjamini-Hochberg correction for multiple pairwise comparisons applied using the dunn.test package (Dinno 2017) in R. $\beta$ Diversity was calculated using Bray-Curtis dissimilarity matrices (Gardener 2014). To account for variation in sequencing depth $(>10 \times)$, reads were scaled for $\beta$-diversity measures (Weiss et al. 2017). Distance matrices were subjected to ordination analyses (principal coordinate analyses) and permutational analysis of variance (PERMANOVA) to test for differences in community centroids.

\section{RESULTS}

Sequencing output. Amplicon sequencing resulted in $2.16 \times 10^{7}$ reads usable in downstream analyses. Only forward reads of $16 \mathrm{~S}$ were used in analysis of bacterial communities because poor reverse-read quality resulted in minimal overlap for joining paired-end reads. Technical replicates were not statistically different for each sample and, therefore, were pooled. All results are pooled across experimental runs, except for $\beta$-diversity analyses, where the experimental runs were statistically different. From the quality-controlled sequences, 16,619 ASVs were inferred, with 11,454 bacterial and 5,165 fungal ASVs. Following removal of chimeras and contaminant ASVs, (i.e., chloroplast, mitochondria, Plantae, and Protista) 10,032 ASVs remained, with 8,811 bacterial and 1,221 fungal ASVs.

Diversity metrics over time and tissue. Shannon diversity of bacterial communities was significantly lower at seedling emergence compared with all other sampling times, whereas there were no differences between the samples taken at 2, 4, and 6 months (Table 1; Fig. 1A). Shannon diversity of bacterial communities was highest in the soil, followed by the rhizosphere, and the lowest in the foliage (Fig. 1A). No significant differences were observed in the Shannon diversity of fungal communities within the study (Fig. 1B).

Within both experimental runs, PERMANOVA results indicated that there were significantly different bacterial and fungal community centroids for both time and tissue sampled (Table 2). Pairwise PERMANOVA showed each time point differing from each other, with a few exceptions (Supplementary Table S1). In experimental run 2, bacterial communities at 6 months postemergence were only significantly different from the 4-month postemergence communities. Bacterial and fungal communities were always significantly different in foliar and soil samples, whereas rhizosphere and soil samples were always similar (Supplementary Table S1). Interestingly, foliar and rhizosphere bacterial and fungal communities were only significantly different in experimental run 2 (Supplementary Table S1). Ordination of distance matrices showed samples clustering by time sampled for both bacterial and fungal communities (Fig. 2). In experimental run 2, foliar and rhizosphere bacterial and fungal communities clustered separately more than in experimental run 1 (Fig. 2).

Changes in taxonomy across time. Bacterial phyla relative abundances were rather consistent over the 6-month sampling period, with phyla at low relative abundances exhibiting the most shifts. Proteobacteria and Cyanobacteria phyla were the largest portion of the community at 3 to 4 and 1.5 to $2 \%$ relative abundance, respectively (Supplementary Fig. S1). At the family level, Burkholderiaceae species were prominent members of the foliage and rhizosphere bacterial communities at emergence ( $2 \%$ relative abundance) but, by 2 months postemergence, their populations decreased $(\leq 0.25 \%$ relative abundance) (Fig. 3). Similarly, Xanthamonadaceae species were present at higher relative abundances at emergence than any other time sampled. Within each time point, taxonomic profiles of the foliage and rhizosphere bacterial communities were different (Fig. 3). After 2 months postemergence, taxa present at very low relative abundances $(<0.1 \%)$ were fluctuating throughout the sampling period more than taxa present at higher relative abundances $(>0.5 \%)$ (Fig. 3 ).

Fungal communities were predominantly composed of Dothideomycetes, Eurotiomycetes, and Sordariomycetes from 2 months postemergence onward (Supplementary Fig. S2). Taxonomic shifts throughout the study primarily occurred with taxa present at higher relative abundances ( $>0.5 \%$ relative abundance) (Fig. 4). At emergence, Trichoderma spp. composed a significant portion of the fungal communities ( 3 to $5 \%$ relative abundance) but decreased steadily until populations reached $<0.25 \%$ relative abundance at 4 and 6 months postemergence (Fig. 4). Conversely, Pleurophragmium increased

TABLE 1

Bacterial community $\alpha$-diversity measures for greenhouse-grown creeping bentgrass

\begin{tabular}{|c|c|c|c|}
\hline \multicolumn{2}{|c|}{ Bacteria } & \multicolumn{2}{|c|}{$\alpha$-Diversity $^{\mathrm{a}}$} \\
\hline Group 1 & Group 2 & $\chi^{2 b}$ & $P$ value ${ }^{c}$ \\
\hline Tissue & & 17.98 & $0.001^{* * *}$ \\
\hline Foliage & Rhizosphere & -3.00 & $0.002 * *$ \\
\hline Foliage & Soil & -3.79 & $0.001^{* * *}$ \\
\hline Rhizosphere & Soil & -1.89 & $0.030 *$ \\
\hline Time & & 37.73 & $0.001^{* * *}$ \\
\hline Emergence & 2 Months & -3.50 & $0.006 * *$ \\
\hline Emergence & 4 Months & -4.13 & $0.001^{* * *}$ \\
\hline Emergence & 6 Months & -4.17 & $0.001 * * *$ \\
\hline 2 Months & 4 Months & -0.63 & 0.292 \\
\hline 2 Months & 6 Months & -0.67 & 0.312 \\
\hline 4 Months & 6 Months & -0.04 & 0.483 \\
\hline \multicolumn{4}{|c|}{$\begin{array}{l}{ }^{a} \text { The } \alpha \text { diversity was calculated as Shannon's diversity index using } \\
\text { phyloseq in R. } \\
\text { b The Kruskal-Wallis } \chi^{2} \text { test statistic was calculated through Kruskal- } \\
\text { Wallis tests using dunn.test in R. } \\
{ }^{c} P \text { values were corrected using Benjamini-Hochberg correction for } \\
\text { multiple comparisons. Asterisks *, **, and }{ }^{* * *} \text { indicate significant at } \\
\text { the } 0.05,0.01 \text {, and } 0.001 \text { probability levels, respectively. }\end{array}$} \\
\hline
\end{tabular}


from 0 to $0.1 \%$ relative abundance at emergence to 2 to $2.5 \%$ relative abundance at 6 months postemergence. Unlike bacterial communities, the taxonomic profiles of foliar and rhizosphere fungal communities were similar within each time point (Figs. 3 and 4).

\section{DISCUSSION}

The goal of this project was to obtain an understanding of community dynamics in the creeping bentgrass microbiome from seedling emergence through 6 months postemergence. The $\alpha$ diversity of bacterial communities was lowest at emergence, while no significant changes in fungal community diversity were observed. Ordination analyses of distance matrices showed samples clustering by sample time, while PERMANOVA also showed that community centroids at each sampling time were different. Taxonomic profiling suggests that the shifts in bacterial community structure over time are driven by changes in taxa present at low relative abundances, whereas shifts in fungal community structure over time are driven by changes in taxa present at high relative abundances.

Ordination of distance matrices and PERMANOVAs revealed that bacterial and fungal communities were changing over time. Because climatic conditions were stable throughout the study, this indicates that plant age influences the turfgrass microbiome. Plant age influencing rhizosphere microbial communities has been observed in Arabidopsis thaliana L. (Chaparro et al. 2014), sweet potato (Marques et al. 2014), soybean (Xu et al. 2009), and wheat (Gdanetz and Trail 2017). These studies were all completed on plants that enter different growth stages as the growing season progresses (e.g., vegetative to flowering). In practice, turfgrasses are maintained in a constant state of vegetative growth through mowing and other management practices. It is interesting that, in the absence of climatic shifts, we observed an influence from plant age from plants that were not entering different growth stages. Perhaps frequent mowing leads to an alteration in plant exudates that could be attributed to these changes as well. However, additional research would be needed to confirm this speculation.
Turfgrasses are unique in that, for their entire lifecycle, the plants are maintained less than an inch to a few inches from the soil surface, depending on the use site. Additionally, the crown is always at the base of maintained turfgrass plants, meaning all new tissue emerges right at the soil surface. As such, one might anticipate turfgrass microbiomes challenging the generally observed phenomenon of microbial diversity decreasing from belowground tissue to aboveground tissue in larger plants. However, our study showed bacterial diversity decreasing from bulk soil to rhizosphere to foliage, whereas fungal diversity did not change between sampled material. Bacterial diversity changes are similar to what has been observed in larger grass plants such as maize and wheat (Gdanetz et al. 2021), other agronomic crops (Dong et al. 2019; Ottesen et al. 2013), and even various tree species (Lambais et al. 2014). Similar foliar and rhizosphere

TABLE 2

Centroid tests of $\beta$-diversity metrics for microbial communities associated with greenhouse-grown creeping bentgrass ${ }^{a}$

\begin{tabular}{|c|c|c|}
\hline \multirow[b]{2}{*}{ Community } & \multicolumn{2}{|c|}{ PERMANOVA $P$ value ${ }^{b}$} \\
\hline & Run 1 & Run 2 \\
\hline \multicolumn{3}{|l|}{ Bacteria } \\
\hline Tissue & $0.022 *$ & $0.001^{* * *}$ \\
\hline Time & $0.001 * * *$ & $0.001 * * *$ \\
\hline \multicolumn{3}{|l|}{ Fungi } \\
\hline Tissue & $0.010 * *$ & $0.002 * *$ \\
\hline Time & $0.001^{* * *}$ & $0.001 * * *$ \\
\hline
\end{tabular}
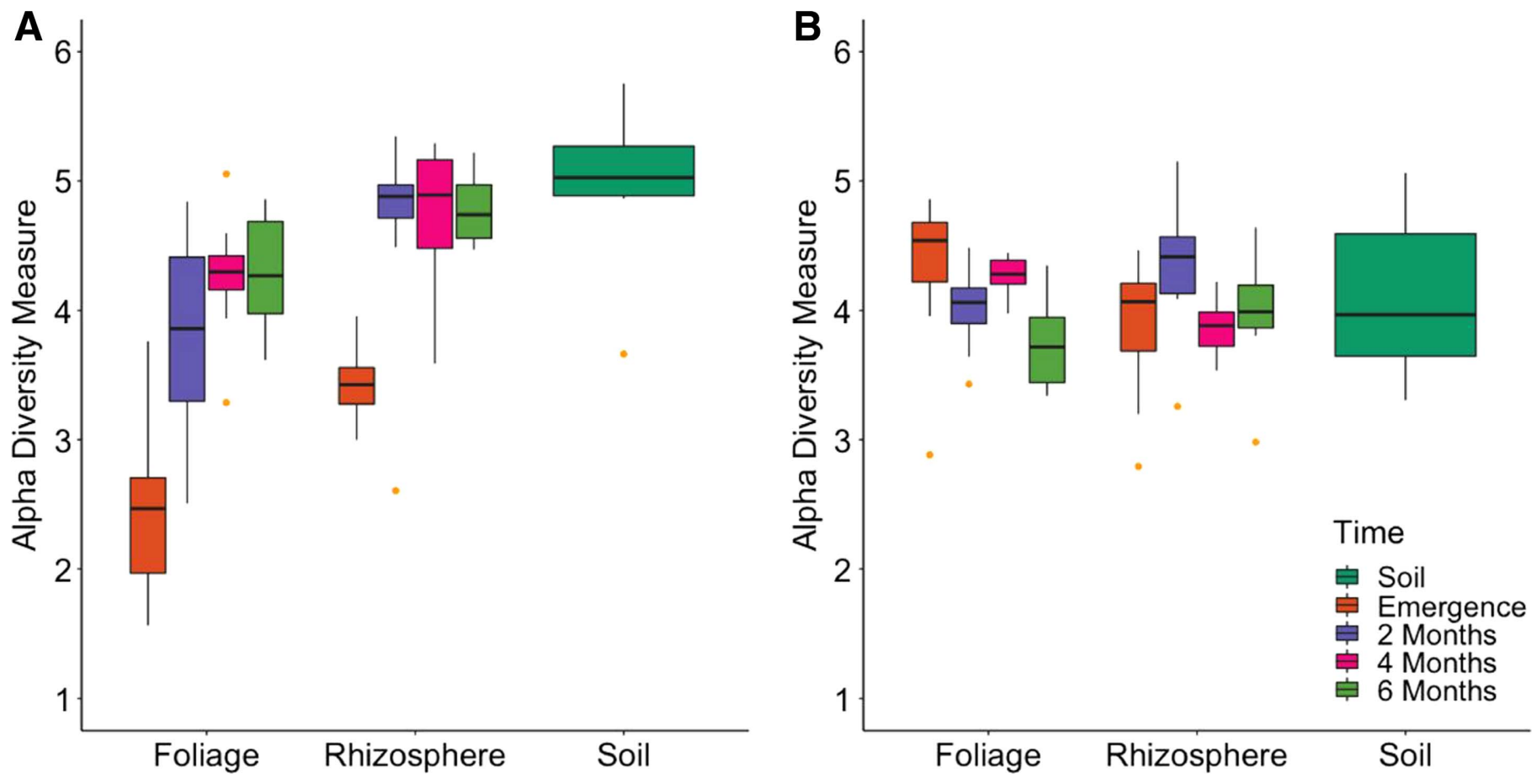

Fig. 1. Shannon diversity measures, calculated using phyloseq in $\mathrm{R}$, for $\mathbf{A}$, bacterial and $\mathbf{B}$, fungal communities associated with greenhouse-grown creeping bentgrass. Higher values indicate higher overall species richness and evenness. Orange points indicate outliers. 
fungal diversity has also been observed in larger plants (ColemanDerr et al. 2016; Gdanetz and Trail 2017). It appears that turfgrass microbiomes follow overarching patterns in microbial diversity similar to those of larger plants. However, it is possible that, under field conditions, where the turfgrass plants are pressed onto the thatch or soil surface from human activities, these patterns may be disrupted and unique patterns may emerge.

Diversity of microbial communities over time was constant. The only significant change occurred in foliar and rhizosphere bacterial communities from emergence to 2 months, whereas there were no changes in fungal community diversity. Results suggest that plant age alone is minimally influential in the overall diversity (i.e., richness and evenness of taxa) of turfgrass-associated bacterial and fungal communities. Under field conditions, diversity has been observed to both increase (Gdanetz and Trail 2017) and remain constant (Sapkota et al. 2017) over time in wheat. There is variation in diversity patterns over time in other systems as well, with diversity increasing in Poa апnиа (Beirn et al. 2016) and olive trees (Materatski et al. 2019), decreasing in maize (Gdanetz et al. 2021) and soybean (Copeland et al. 2015), and remaining constant in grape (Manici et al. 2017). Taking our findings into account, this suggests that, under field settings, seasonality plays a significant role in the diversity of microbial communities. However, it is important to consider that perhaps the observed consistency in microbial diversity in this study stems from attenuated external influences (e.g., environmental changes) or from the turfgrass remaining in constant vegetative growth. Future research projects under field conditions would be needed to see whether microbial community diversity changes over time in response to seasonality or management practices.

The data suggest that changes in bacterial community structure are driven by relatively rare taxa (i.e., taxa present at $<0.5 \%$ relative abundance). Ordination and statistical analysis indicate that communities differ between sampling times while changes in taxonomic composition between sampling times is mostly relegated to these relatively rare taxa after 2 months postemergence. Our previous study under sterile growth conditions also observed low-relative-abundance taxa driving bacterial community changes over time (Doherty et al. 2020). Although functional redundancy might suggest that rare species may not be of importance, prior research suggests that this may not be true. Production of antifungal compounds that reduced hyphal growth of Fusarium oxysporum was lost as soil bacterial species richness decreased (Hol et al. 2015). Removal of rare microbial species from the soil increased plant biomass of Beta vulgaris and $B$. oleracea but these plants were also more suitable for herbivores due to a decrease in defensive compounds present compared with plants grown in unaltered soil (Hol et al. 2010). A review of the literature on microbial communities has illustrated the role that rare microbial species in a community play in critical ecosystem services such as
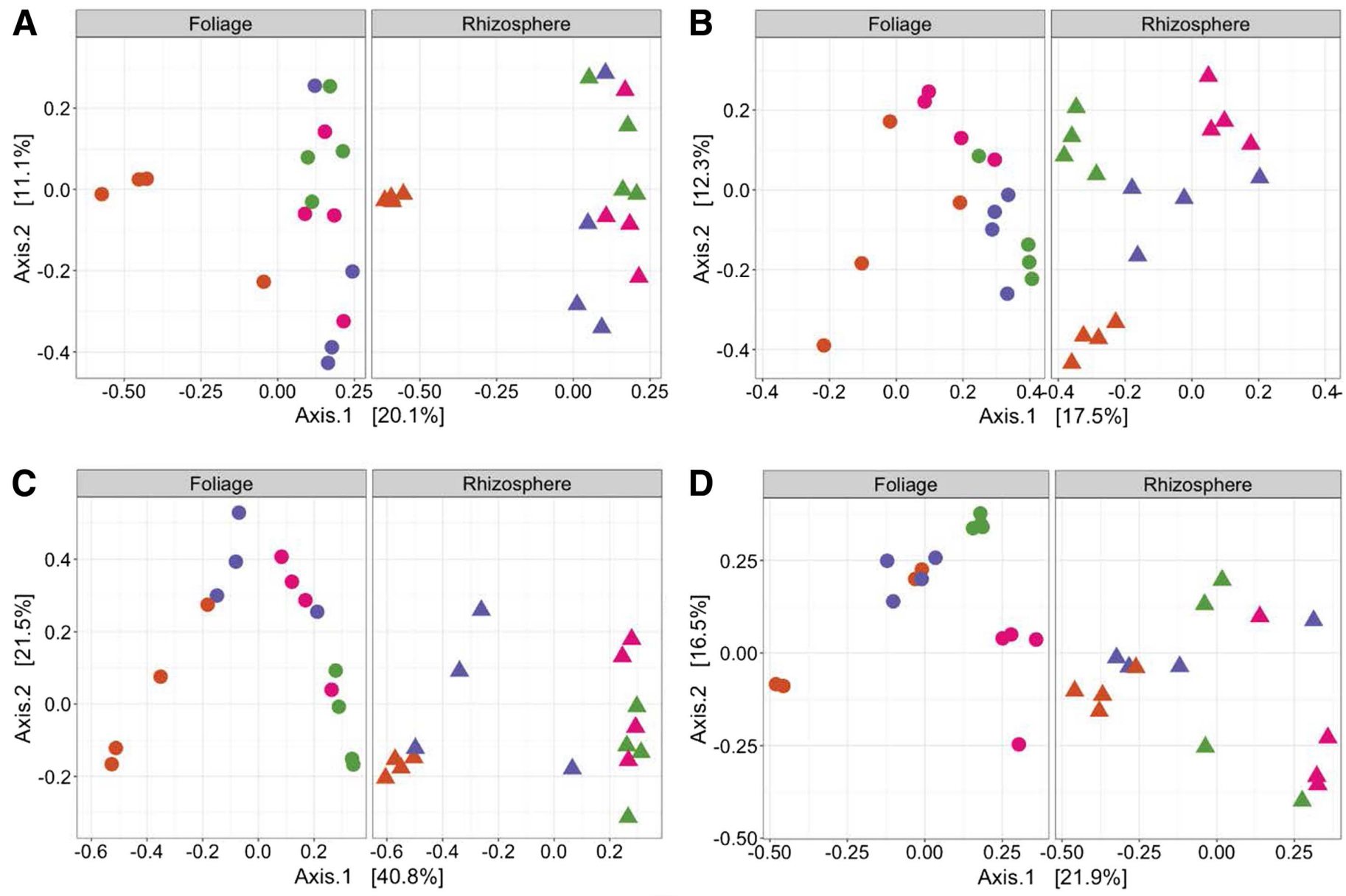

Time

\section{Soil Emergence 2 Months 4 Months 6 Months}

Fig. 2. Principal component analysis, completed using phyloseq in $R$, of Bray-Curtis distance matrices, calculated in phyloseq, of $\mathbf{A}$ and $\mathbf{B}$, bacterial and $\mathbf{C}$ and $\mathbf{D}$, fungal communities of experimental run 1 ( $A$ and $C$ ) and experimental run 2 ( $B$ and $D)$. Values in brackets indicate percent variation explained by that axis. 


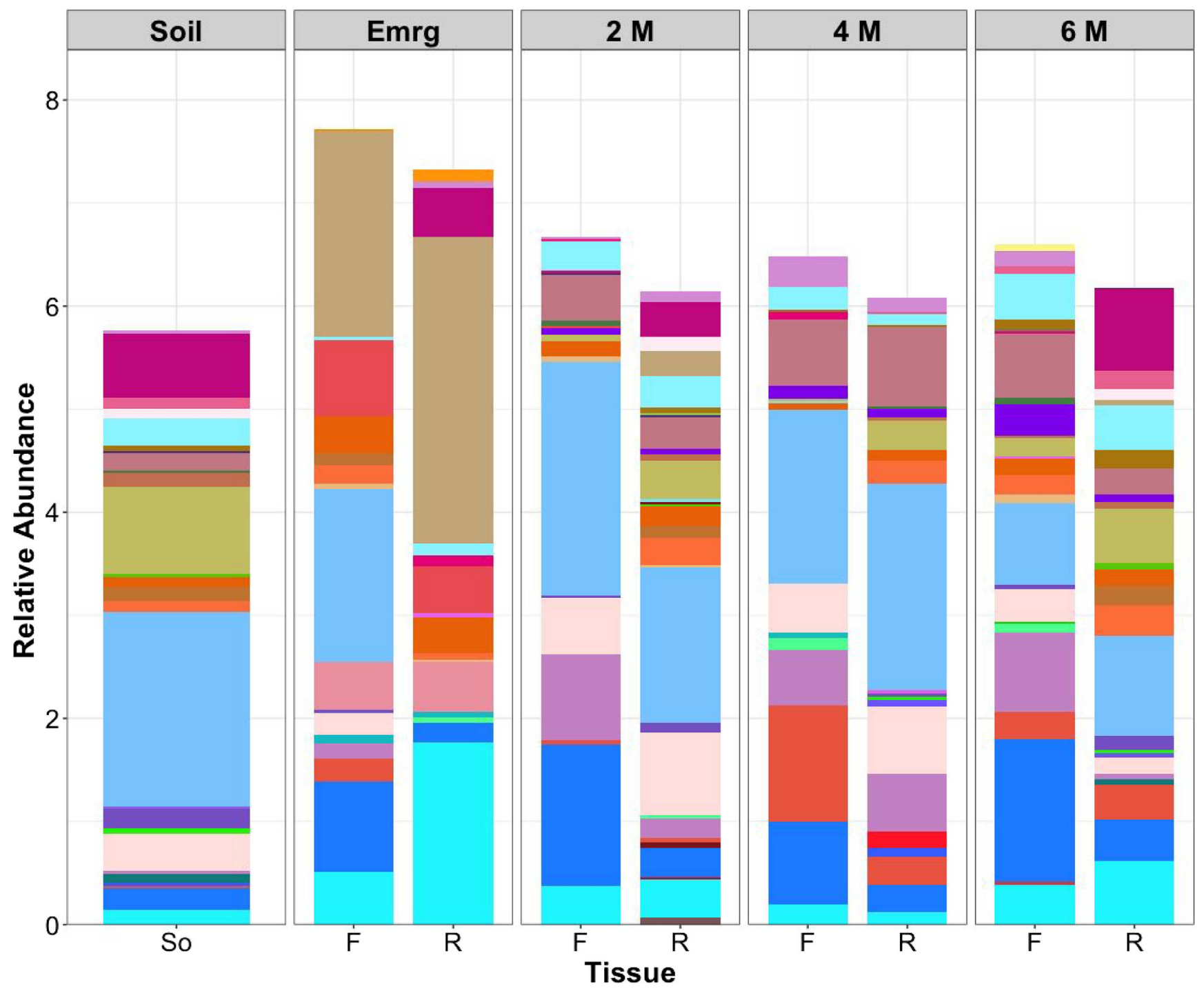

Family

\begin{tabular}{|c|c|c|}
\hline $\begin{array}{l}\text { briimonadaceae] } \\
\text { ksellaceae] } \\
\text { obacteraceae } \\
\text { obacteriaceae } \\
\text { losynnemataceae } \\
\text { ntimonadaceae } \\
\text { yrhizobiaceae } \\
\text { holderiaceae } \\
\text { obacteraceae } \\
\text { nophagaceae } \\
\text { roflexaceae } \\
\text { lamonadaceae } \\
\text { exibacteraceae } \\
\text { morphaceae } \\
\text { phagaceae } \\
6075\end{array}$ & $\begin{array}{l}\text { ythrobacteraceae } \\
\text { emmataceae } \\
\text { yphomicrobiaceae } \\
\text { yphomonadaceae } \\
\text { neosporiaceae } \\
\text { ethylobacteriaceae } \\
\text { ethylocystaceae } \\
\text { icrobacteriaceae } \\
\text { ycobacteriaceae } \\
\text { ocardioidaceae } \\
\text { ostocaceae } \\
\text { 28 } \\
\text { xalobacteraceae } \\
\text { aenibacillaceae }\end{array}$ & $\begin{array}{l}\text { aceae } \\
\text { naceae } \\
\text { laceae } \\
\text { liaceae } \\
\text { ceae } \\
\text { eae } \\
\text { le } \\
\text { eae } \\
\text { ae } \\
\text { iaceae } \\
\text { daceae } \\
\text { ceae } \\
\text { iaceae } \\
\text { aceae }\end{array}$ \\
\hline
\end{tabular}

Fig. 3. Relative abundances, calculated using phyloseq in $\mathrm{R}$, of bacterial families associated with greenhouse-grown creeping bentgrass. Abbreviations: So, F, and R, indicate soil, foliar, and rhizosphere samples, respectively. Emrg, $2 \mathrm{M}, 4 \mathrm{M}$, and $6 \mathrm{M}$ indicate samples taken at emergence and 2, 4 , and 6 months, respectively. 
nutrient cycling, pollutant degradation, community assembly, and host health (Jousset et al. 2017). The potential role that rare species play in ecosystem services may warrant revising analysis methods to make informed decisions on removal of rare observations (e.g., singletons or taxa with low prevalence across samples).

This research builds upon our prior work investigating the primary influences on the juvenile creeping bentgrass microbiome (Doherty et al. 2020). Our previous work sought to discern the influence that seed and soil exerted on the juvenile microbiome. Although soil microbiota appeared to play a significant role in determining taxa present compared with seed microbiota, the influence of the creeping bentgrass plants appeared to overpower these influences because the microbiome communities were similar between creeping bentgrass grown in autoclaved and nonautoclaved soil (Doherty et al. 2020). Unlike our initial work, this current research observed significant differences in fungal community centroids over time. This indicates that shifts in fungal communities occur more slowly than in bacterial communities, where our initial work observed significantly different bacterial community centroids within the 6-week study
(Doherty et al. 2020). These new results suggest that fungal communities are not as stable as our initial work suggested. Interestingly, both studies observed rare and common taxa driving differences in bacterial and fungal communities, respectively, despite the presence of external inoculum in the greenhouse. Given these similarities, the plant appears to be why these community dynamics occur in this manner. Combined, these two studies provide a basic understanding of the creeping bentgrass microbiome and provide a framework for future microbiome research on different turfgrass species or under field conditions.

Research presented here illustrates that microbial communities associated with creeping bentgrass are influenced more by plant age than by plant compartment. Although community diversity may not have changed over time, community centroids and taxonomic profiling highlight changes in communities over time. Rare bacterial and predominant fungal taxa appear to be driving fluctuations of their respective communities during the 6-month period following seedling emergence. Furthermore, despite a significant difference in the proximity to the soil surface compared with agronomic grasses or other

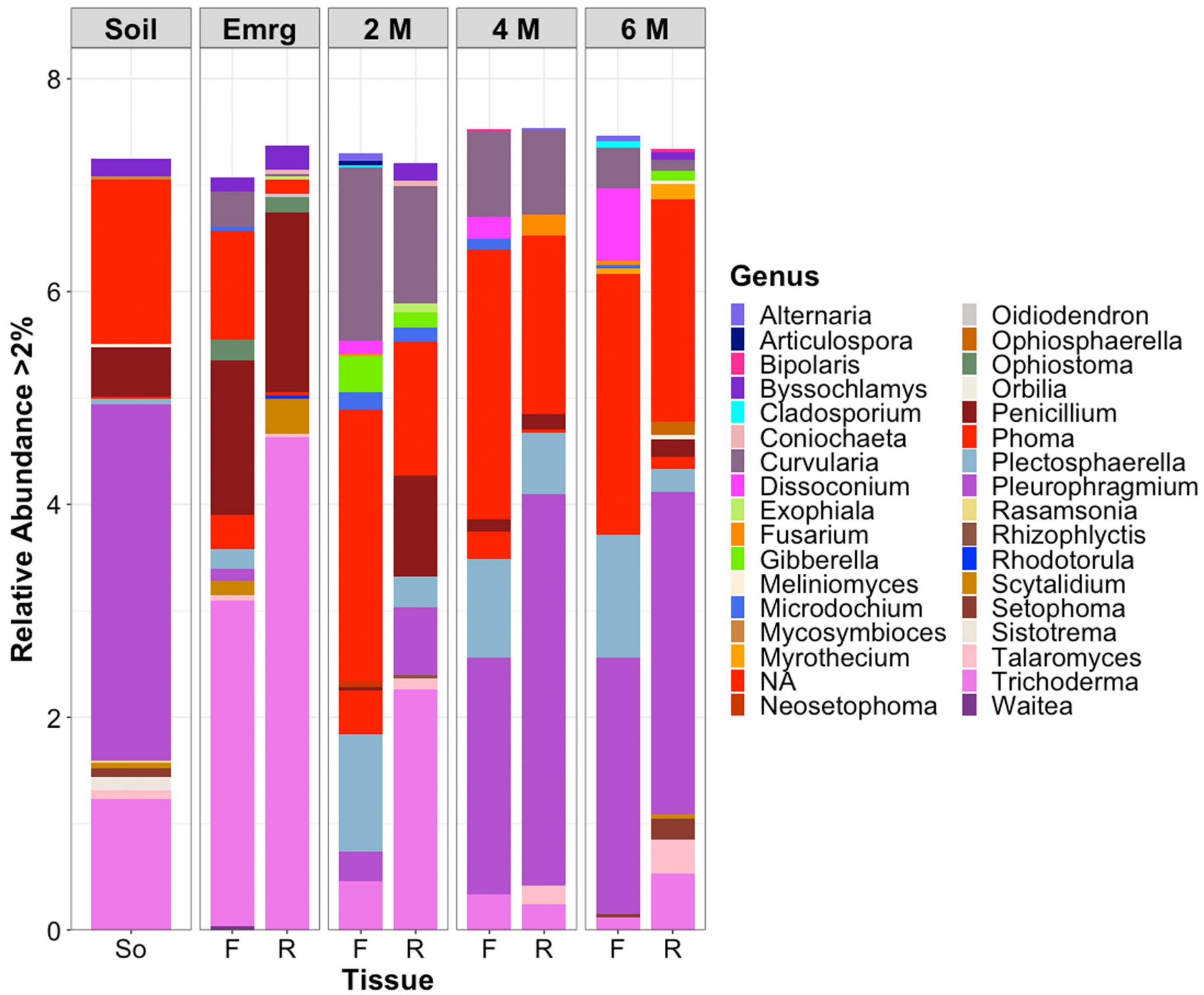

Fig. 4. Relative abundances, calculated using phyloseq in $\mathrm{R}$, of fungal genera associated with greenhouse-grown creeping bentgrass. Abbreviations: So, F, and R, indicate soil, foliar, and rhizosphere samples, respectively. Emrg, $2 \mathrm{M}, 4 \mathrm{M}$, and $6 \mathrm{M}$ indicate sampling times of emergence and 2, 4, and 6 months, respectively. 
crops, the microbiome of turfgrass in this study follows some of the same patterns observed in these larger plants. Additional research is needed in the field to see whether the relationships described in this controlled-environment study hold true under real-world scenarios, where management practices and human traffic may lead to significant departures from the patterns we observed here. The controlled greenhouse environment used for this study, while necessary to ascertain community shifts driven by the turfgrass, reduced external factors that would undoubtably alter the microbiome. For example, reduced external influences coupled with the frequent irrigation through overhead misters may have contributed to the high proportions of Cyanobacteria we observed. Long-term field studies will be necessary to understand how the turfgrass microbiome is responding to environmental and human-induced stressors. The work presented here contributes to the increasing pool of knowledge about the turfgrass microbiome, which will provide foundational information for future turfgrass microbiome research investigating management-related impacts on the turfgrass microbiome.

\section{ACKNOWLEDGMENTS}

We thank C. Salgado for assistance in troubleshooting multiple steps of this project, D. Veltri for developing custom data parsing scripts and guidance in bioinformatic analyses, and S. Wallace and M. Fisher-Holbert of the Plant Growth Facility for their assistance in maintaining environmental conditions within the greenhouse. Mention of trade names or commercial products in this publication is solely for the purpose of providing specific information and does not imply recommendation or endorsement by the USDA. USDA is an equal opportunity provider and employer.

\section{LITERATURE CITED}

Adesemoye, A. O., Torbert, H. A., and Kloepper, J. W. 2009. Plant growthpromoting rhizobacteria allow reduced application rates of chemical fertilizers. Microb. Ecol. 58:921-929.

Andrews, J. H. 1992. Biological control in the phyllosphere. Annu. Rev. Phytopathol. 30:603-635.

Bakker, M. G., Manter, D. K., Sheflin, A. M., Weir, T. L., and Vivanco, J. M. 2012. Harnessing the rhizosphere microbiome through plant breeding and agricultural management. Plant Soil 360:1-13.

Beirn, L. A., Hempfling, J. W., Schmid, C. J., Murphy, J. A., Clarke, B. B., and Crouch, J. A. 2016. Differences among soil-inhabiting microbial communities in Poa annua turf throughout the growing season. Crop Sci. 57: S-262-S-273.

Berendsen, R. L., Pieterse, C. M. J., and Bakker, P. A. H. M. 2012. The rhizosphere microbiome and plant health. Trends Plant Sci. 17:478-486.

Callahan, B. J. 2016. The RDP and Greengenes taxonomic training sets formatted for DADA2. Zenodo.

Callahan, B. J., McMurdie, P. J., Rosen, M. J., Han, A. W., Johnson, A. J. A., and Holmes, S. P. 2016. DADA2: High-resolution sample inference from Illumina amplicon data. Nat. Methods 13:581-583.

Chaparro, J. M., Badri, D. V., and Vivanco, J. M. 2014. Rhizosphere microbiome assemblage is affected by plant development. ISME J. 8: 790-803.

Coleman-Derr, D., Desgarennes, D., Fonseca-Garcia, C., Gross, S., Clingenpeel, S., Woyke, T., North, G., Visel, A., Partida-Martinez, L. P., and Tring, S. G. 2016. Plant compartment and biogeography affect microbiome composition in cultivated and native Agave species. New Phytol. 209:798-811.

Copeland, J. K., Yuan, L., Layeghifard, M., Wang, P. W., and Guttman, D. S. 2015. Seasonal community succession of the phyllosphere microbiome. Mol. Plant-Microbe Interact. 28:274-285.

Crouch, J. A., Carter, Z., Ismaiel, A., and Roberts, J. A. 2017. The US National Mall microbiome: A census of rhizosphere bacteria inhabiting landscape turf. Crop Sci. 57:S-341-S-348.

Dinno, A. 2017. dunn.test: Dunn's test of multiple comparisons using rank sums. https://cran.r-project.org/web/packages/dunn.test/index.html
Doherty, J. R., Botti-Marino, M., Kerns, J. P., Ritchie, D. F., and Roberts, J. A. 2017. Response of microbial populations on the creeping bentgrass phyllosphere to periodic fungicide applications. Plant Health Prog. 18: 44-49.

Doherty, J. R., Crouch, J. A., and Roberts, J. A. 2020. Elucidating the influence of resident seed and soil microbiota on the developing creeping bentgrass microbiome. Agrosyst. Geosci. Environ. 3:e20038.

Dong, C.-J., Wang, L.-L., Li, Q., and Shang, Q.-M. 2019. Bacterial communities in the rhizosphere, phyllosphere and endosphere of tomato plants. PLoS One 14:e0223847.

Fadrosh, D. W., Ma, B., Gajer, P., Sengamalay, N., Ott, S., Brotman, R. M., and Ravel, J. 2014. An improved dual-indexing approach for multiplexed 16S rRNA gene sequencing on the Illumina MiSeq platform. Microbiome 2:6.

Gardener, M. 2014. Community Ecology: Analytical Methods using R and Excel. Pelagic Publishing, Exeter, UK.

Gdanetz, K., Noel, Z., and Trail, F. 2021. Influence of plant host and organ, management strategy, and spore traits on microbiome composition. Phytobiomes J. 5:202-1219.

Gdanetz, K., and Trail, F. 2017. The wheat microbiome under four management strategies, and potential for endophytes in disease protection. Phytobiomes J. 1:158-168.

Grady, K. L., Sorensen, J. W., Stopnisek, N., Guittar, J., and Shade, A. 2019. Assembly and seasonality of core phyllosphere microbiota on perennial biofuel crops. Nat. Commun. 10:4135.

Hartmann, M., Frey, B., Mayer, J., Mäder, P., and Widmer, F. 2014. Distinct soil microbial diversity under long-term organic and conventional farming. ISME J. 9:1177-1194.

Hoagland, D. R., and Arnon, D. I. 1950. The water-culture method for growing plants without soil. Calif. Agric. Exp. Stn. Circ. 347:1-32.

Hol, W. H. G., De Boer, W., Termorshuizen, A. J., Meyer, K. M., Schneider, J. H. M., Van Dam, N. M., Van Veen, J. A., and Van Der Putten, W. H. 2010. Reduction of rare soil microbes modifies plant-herbivore interactions. Ecol. Lett. 13:292-301.

Hol, W. H. G., Garbeva, P., Hordijk, C., Hundscheid, M. P. J., Gunnewiek, P. J. A. K., van Agtmaal, M., Kuramae, E. E., and de Boer, W. 2015. Nonrandom species loss in bacterial communities reduces antifungal volatile production. Ecology 96:2042-2048.

Jousset, A., Bienhold, C., Chatzinotas, A., Gallien, L., Gobet, A., Kurm, V., Küsel, K., Rillig, M. C., Rivett, D. W., Salles, J. F., van der Heijden, M. G. A., Youssef, N. H., Zhang, X., Wei, Z., and Hol, W. H. G. 2017. Where less may be more: How the rare biosphere pulls ecosystems strings. ISME J. 11: 853-862.

Kittelmann, S., Seedorf, H., Walters, W. A., Clemente, J. C., Knight, R., Gordon, J. I., and Janssen, P. H. 2013. Simultaneous amplicon sequencing to explore co-occurrence patterns of bacterial, archaeal and eukaryotic microorganisms in rumen microbial communities. PLoS One 8:e47879.

Kõljalg, U., Nilsson, R. H., Abarenkov, K., Tedersoo, L., Taylor, A. F. S., Bahram, M., Bates, S. T., Bruns, T. D., Bengtsson-Palme, J., Callaghan, T. M., Douglas, B., Drenkhan, T., Eberhardt, U., Dueñas, M., Grebenc, T., Griffith, G. W., Hartmann, M., Kirk, P. M., Kouhout, P., Larsson, E., Lindahl, B. D., Lücking, R., Martin, M. P., Matheny, P. B., Nguyen, N. H., Niskanen, T., Oja, J., Peay, K. G., Peintner, U., Peterson, M., Põldmaa, K., Saag, L., Saar, I., Schüßler, A., Scott, J. A., Senés, C., Smith, M. E., Suija, A., Taylor, D. L., Telleria, M. T., Weiss, M., and Larsson, K.-H. 2013. Towards a unified paradigm for sequence-based identification of fungi. Mol. Ecol. 22:5271-5277.

Lambais, M. R., Lucheta, A. R., and Crowley, D. E. 2014. Bacterial community assemblages associated with the phyllosphere, dermosphere, and rhizosphere of tree species of the Atlantic forest are host taxon dependent. Microb. Ecol. 68:567-574.

Lambers, H., Mougel, C., Jaillard, B., and Hinsinger, P. 2009. Plant-microbesoil interactions in the rhizosphere: An evolutionary perspective. Plant Soil 321:83-115.

Latin, R. 2011. Scheduling fungicides for turf disease control. Pages 137-156 in: A Practical Guide to Turfgrass Fungicides. The American Phytopathological Society, St. Paul, MN, U.S.A.

Ma, L., Rocha, F. I., Lee, J., Choi, J., Tejera, M., Sooksa-Nguan, T., Boersma, N., VanLoocke, A., Heaton, E., and Howe, A. 2021. The impact of stand age and fertilization on the soil microbiome of Miscanthus $\times$ giganteus. Phytobiomes J. 5:51-59.

Manici, L. M., Saccà, M. L., Caputo, F., Zanzotto, A., Gardiman, M., and Fila, G. 2017. Long- term grapevine cultivation and agro-environment affect rhizosphere microbiome rather than plant age. Appl. Soil Ecol. 119:214-225. 
Marques, J. M., da Silva, T. F., Vollu, R. E., Blank, A. F., Ding, G.-C., Seldin, L., and Smalla, K. 2014. Plant age and genotype affect the bacterial community composition in the tuber rhizosphere of field-grown sweet potato plants. FEMS Microbiol. Ecol. 88:424-435.

Martin, M. 2011. Cutadapt removes adapter sequences from high-throughput sequencing reads. EMBnet. J. 17:10-12.

Materatski, P., Varanda, C., Carvalho, T., Dias, A. B., Campos, M. D., Rei, F., and Félix, M. R. 2019. Spatial and temporal variation of fungal endophytic richness and diversity associated to the phyllosphere of olive cultivars. Fungal Biol. 123:66-76.

McDonald, D., Price, M. N., Goodrich, J., Nawrocki, E. P., DeSantis, T. Z., Probst, A., Andersen, G. L., Knight, R., and Hugenholtz, P. 2012. An improved Greengenes taxonomy with explicit ranks for ecological and evolutionary analyses of bacteria and archaea. ISME J. 6:610-618

McMurdie, P. J., and Holmes, S. 2013. phyloseq: An R package for reproducible interactive analysis and graphics of microbiome consensus data. PLoS One 8:e61217.

McMurdie, P. J., and Holmes, S. 2014. Waste not, want not: Why rarefying microbiome data is inadmissible. PLOS Comput. Biol. 10:e1003531.

Oksanen, J., Blanchet, F. G., Friendly, M., Kindt, R., Legendre, P., McGlinn, D., Minchin, P. R., O’Hara, R. B., Simpson, G. L., Solymos, P., Stevens, M. H. H., Szoecs, E., and Wagner, H. 2017. vegan: Community Ecology Package. R package version 2.4-5. https://cran.r-project.org/web/packages/ vegan/index.html

Ottesen, A. R., González Peña, A., White, J. R., Pettengill, J. B., Li, C., Allard, S., Rideout, S., Allard, M., Hill, T., Evans, P., Strain, E., Musser, S., Knight, R., and Brown, E. 2013. Baseline survey of the anatomical microbial ecology of an important food plant: Solanum lycopersicum (tomato). BMC Microbiol. 13:114.

R Core Team. 2017. R: A language and environment for statistical computing. R Foundation for Statistical Computing, Vienna, Austria. https://www. R-project.org/
Sapkota, R., Jørgensen, L. N., and Nicolaisen, M. 2017. Spatiotemporal variation and networks in the mycobiome of the wheat canopy. Front. Plant Sci. 8:1357.

Spellerberg, I. F., and Fedor, P. J. 2003. A tribute to Claude Shannon (1916-2001) and a plea for more rigorous use of species richness, species diversity and the 'Shannon-Wiener' index. Glob. Ecol. Biogeogr. 12:177179.

Toju, H., Tanabe, A. S., Yamamoto, S., and Sato, H. 2012. High-coverage ITS primers for the DNA-based identification of ascomycetes and basidiomycetes in environmental samples. PLoS One 7:e40863.

Turner, T. 2013. Nutrient management guidelines for golf courses in Maryland. University of Maryland Turfgrass Technical Update TT118. University of Maryland. https://mda.maryland.gov/SiteAssets/Pages/fertilizer/TT118.pdf

Weisburg, W. G., Barns, S. M., Pelletier, D. A., and Lane, D. J. 1991. 16S ribosomal DNA amplification for phylogenetic study. J. Bacteriol. 173:697703.

Weiss, S., Xu, Z. Z., Peddada, S., Amir, A., Bittinger, K., Gonzalez, A., Lozupone, C., Zaneveld, J. R., Vázquez-Baeza, Y., Birmingham, A., Hyde, E. R., and Knight, R. 2017. Normalization and microbial differential abundance strategies depend upon data characteristics. Microbiome 5:27.

White, T. J., Bruns, T., Lee, S., and Taylor, J. 1990. Amplification and direct sequencing of fungal ribosomal RNA genes for phylogenetics. M. A. Innis, D. H. Gelfand, J. J. Sninsky, and T. J. White, eds. Pages 315-322 in: PCR Protocols: A Guide to Methods and Applications. Academic Press, San Diego, CA, U.S.A.

Wickham, H. 2009. ggplot2: Elegant Graphics for Data Analysis. SpringerVerlag, New York, NY, U.S.A. https://ggplot2-book.org/

Xu, Y., Wang, G., Jin, J., Liu, J., Zhang, Q., and Liu, X. 2009. Bacterial communities in soybean rhizosphere in response to soil type, soybean genotype, and their growth stage. Soil Biol. Biochem. 41:919-925.

Yao, H., Bowman, D., and Shi, W. 2011. Seasonal variations of soil microbial biomass and activity in warm- and cool-season turfgrass systems. Soil Biol. Biochem. 43:1536-1543. 